\title{
$\mathrm{n}$ 型 $\mathrm{Fe}_{0.98} \mathrm{Co}_{0.02} \mathrm{Si}_{2}$ の熱電特性に及ぼす $\mathrm{Al}$ 添加の影響
}

\author{
永井宏汸，田畑 貴史饮，勝山茂汭，真島一彦杄

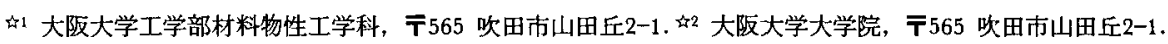

\section{Effect of Al Addition on the Thermoelectric Properties of n-type $\mathrm{Fe}_{0.98} \mathrm{Co}_{0.02} \mathrm{Si}_{2}$}

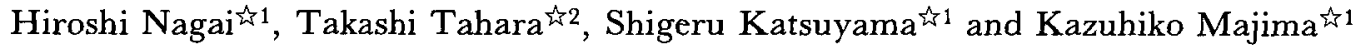 \\ it Department of Materials Science and Engineering, Osaka Univ., 2-1 Yamadaoka, Suita 565. \&2 Graduate \\ School, Osaka University, 2-1 Yamadaoka, Suita 565.
}

Received July 28, 1995

\section{SYNOPSIS}

The effect of $\mathrm{Al}$ addition on the thermoelectric properties of n-type Fe0.88Co0.02Si2 were investigated for $\mathrm{Fe} 0.98 \mathrm{Co0.02} \mathrm{Si}_{2} \times \mathrm{Alx}(0 \leqq \mathrm{X} \leqq 0.1)$ and $\mathrm{Fe}_{0.98} \mathrm{Co0}_{0.02} \mathrm{Si}_{2}+\mathrm{ywt} \% \mathrm{Al}(0 \leqq \mathrm{y} \leqq 6)$. Mixture of $\mathrm{Fe}, \mathrm{Si}$ and $\mathrm{Co}$ powders with or without $\mathrm{Al}$ were arc-melted in an argon atmosphere to form a button composed of $\alpha-\mathrm{Fe}_{2} \mathrm{Si}_{5}$ and $\varepsilon$-FeSi phases. The button was ground under $60 \mathrm{mesh}$ and $\mathrm{Al}$ powder was mixed for $\mathrm{Fe} .98 \mathrm{Co0.02} \mathrm{Si}$ powder. Then they were ground (MA) in a conventional ball mill for $360 \mathrm{ks}$. $\quad \beta-\mathrm{FeSi}_{2}$ phase was not formed during MA, but was obtained by hot pressing of MA powders at $1173 \mathrm{~K}$ for $1.8 \mathrm{ks}$ under $25 \mathrm{MPa}$. It was found that the thermoelectric properties of $\mathrm{Fe} 0.98 \mathrm{Co0.02} \mathrm{Si}$ was drastically changed by the ddition of $\mathrm{Al}$. The resistivity of $\mathrm{Fe}_{0.98} \mathrm{Co0}_{02} \mathrm{Si}_{2}$ increased with increasing $\mathrm{Al}$ addition and reached at maximum at $x=0.04$ and $y=1$, respectively and thereafter decreased again for higher Al content. Thermoelectric power decreased with increasing $\mathrm{Al}$ addition and the property drastically changed from $n$-type $(x \leqq 0.04),(y \leqq 1)$ to p-type $(x \geqq 0.06),(y \geqq 2)$. As a result, the power factor $\left(\mathrm{Q}^{2 / \rho} \rho\right)$ of $\mathrm{Fe} 0.98 \mathrm{Co0.02 \textrm {Si }}$ decreased with increasing $\mathrm{Al}$ addition. On the other hand, the thermal conductivity of $\mathrm{Fe}_{0.98} \mathrm{Co}_{0.02} \mathrm{Si}_{2}$ slightly increased with increasing $\mathrm{Al}$ addition due to the increase in the heat capacity.

\section{KEY WORDS}

$\beta-\mathrm{FeSi}_{2}$, thermoelectric material, resistivity, thermal conductivity, mechanical alloying

\section{1 緒 言}

熱電変換材料としての $\beta-\mathrm{FeSi}_{2}$ は耐熱性や原料コ スト等の点で他の熱電材料より優れているため, その 実用化が期待されているが, 1)-4) 実用化を広範囲に進 めて行くには，その性能および製造プロセスをさらに
改善するために，添加元素あるいは不純物の影響を把 提しておく必要がある.

一方、 $\beta \cdot \mathrm{FeSi}_{2}$ 金属間化合物の製造には，㸮末冶金 法が適しているか，高密度の焼結体を得ることは容易 ではない，前報 5) で筆者らは， $\mathrm{Cu}$ 添加によって $\beta$. 
$\mathrm{FeSi}_{2}$ の液相焼結が可能であることを報告した。 また， $\mathrm{Cu}$ 添加は $\beta$ 相中に $\varepsilon$ 金属相粒子の分散量を増大させ る効果を示し，電気抵抗を低下させることにより $\mathrm{n}$ 型 $\mathrm{FeSi}_{2}$ の熱電特性の改善には有効であるが, 5)6) $\mathrm{p}$ 型 $\mathrm{FeSi}_{2}$ の熱電特性には悪影響を及ぼすことを明らかに した.5)このことは，金属相の存在が熱電特性に複雑 な影響を及ぼすことを示しており,78) その影響を明 確にする必要がある.

本䂨究では, $\mathrm{p}$ 型添加元素であるが, 液相焼結のため の添加元素として有効であると予想される Alを取り 上げ, $\mathrm{n}$ 型 $\mathrm{Fe} 0.98 \mathrm{C} 00.02 \mathrm{Si}_{2}$ の熱電特性に及ぼす $\mathrm{Al}$ 添加 の効果について検討した。

\section{2 実䟻方法}

本研究では，Fe0.98Co0.02Si2.xAlx(x=0〜0.1)[A-1]お よび $\mathrm{Fe} 0.98 \mathrm{Co}_{0.02 \mathrm{Si} 2}$ [A-2]の組成を有する武料をアーク 溶解した，それらを鉄製乳鉢で -60mesh まで粉砕 し，[A-1]試料はそのまま，[A-2] 試料については, Fe0.98Co0.02Si2 + ywt\%Al(y=0〜6)の組成になるように $\mathrm{Al}$ 粉末を添加して, $\mathrm{Ar}$ 萦囲気中で回転数 $120 \mathrm{rpm}$ で 100 時間ボールミルした. 得られた㸮末をカーボン・ ダイスを用いて, $10^{-2} \mathrm{~Pa}$ 以下の真空中, $900^{\circ} \mathrm{C}, 25 \mathrm{MPa}$ で30min ホットプレスした. このようにして得られ た焼結体について，XRD による相同定，EPMAによる 組織観察と分析, 熱起電力, 電気抵抗およびレーザ 一・フラッシュ法（真空理工社製 TC-7000)による熱 伝導率の测定を行い， $\mathrm{n}$ 型 $\mathrm{Fe} 0.98 \mathrm{Co0} .02 \mathrm{Si}_{2}$ の熱電特性に 及ぼす $\mathrm{Al}$ 添加の影響について検討した。

\section{3 実給果及び考察}

\section{3-1 $\beta$ 相形成プロセス}

一例として, Fig.1にアーク溶解後(a), ボールミル後 (b)およびホットプレス後のX線回折結果を示す.

図より明らかなように,アーク溶解試料(a)は状㦔図か ら予想される通り $\alpha$ 相 $\left(\mathrm{Fe}_{2} \mathrm{Si}\right.$ ) $) \varepsilon$ 相 $(\mathrm{FeSi})$ からなっ ており、ボールミル(b)してもピークはブロードになる が， $\beta$ 相は形成していない．しかしながら, $900^{\circ} \mathrm{Cで}$ $30 \mathrm{~min}$ 間ホットプレスするだけで，Fig.1(c)に見られ るように，僅かに $\varepsilon$ 相を含むが殆ど $\beta$ 相化しており， MA とホットプレスの組み合わせによって, 著しく $\beta$ 相化が促進される. この傾向は Fe0.98Co0.02Si2xAlx $(0 \leqq x \leqq 0.10)$ では変わらないか， $\mathrm{Fe}_{0.98} \mathrm{Co}_{0.02 \mathrm{Si}_{2}+}$ ywt\%Al の場合には，Fig.2に見られるように $\mathrm{y} \geq 5$ で殆
ど $\alpha$ 相のみとなる， $\mathrm{y}=5$ の $\mathrm{Al}$ 濃度は，ほぼ $\mathrm{X}=0.2$ に 相当するから，多量の $\mathrm{Al}$ が $\mathrm{Si}$ サイトを占めるためで あると考えられる。

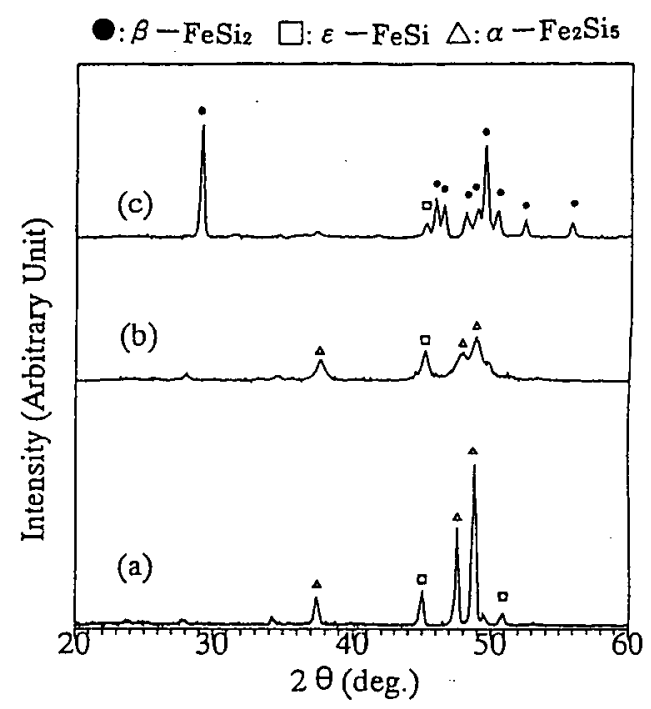

Fig.1 X-ray diffraction patterns of Feo.98 $\mathrm{Co0}_{0.02 \mathrm{Si}} \cdot \mathrm{xAl} \mathrm{X}(\mathrm{X}=0.01)$
(a) as arc-melted,
(b) MA for $100 \mathrm{hr}$.
(c) as hot-pressed.

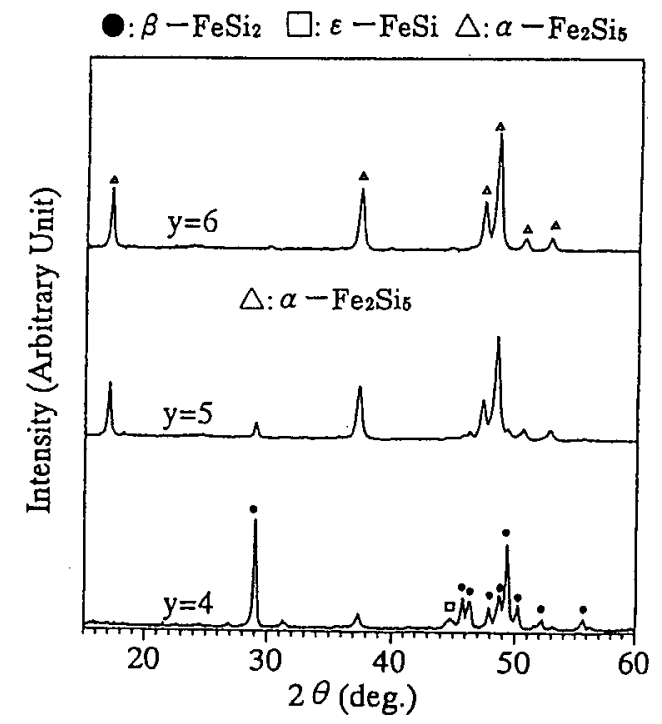

Fig.2 X-ray diffraction patterns of $\mathrm{Fe}_{0.98} \mathrm{Co0.02}_{0 .} \mathrm{Si}_{2}+\mathrm{ywt} \% \mathrm{Al}(\mathrm{y}=0 \sim 6)$.

Fe0.98Co0.02Si $2 \times x A l x$ および $\mathrm{Fe}_{0.98} \mathrm{Coo}_{02} \mathrm{Si}_{2}+\mathrm{ywt} \% \mathrm{Al}$ 木 ットプレス材の組織は，いずれも $\beta$ 相内に微細な $\varepsilon$ 相 粒子が分散した組織をしており， $\varepsilon$ 相の量はAl添加量 
の增大に伴って増加する傾向を示すが, $\mathrm{x} \geqq 0.04$ では $\varepsilon$ 相の量は減少し, Si 粒子の量が增大する。

\section{3-2 電気抵抗}

Fe0.88C00.02Si2.xAlx の電気抵抗 $\log \rho$ と $1 / \mathrm{T}$ の関係 を, $\mathrm{x} \leqq 0.04$ につて Fig.3に, $0.06 \leqq x \leqq 0.10$ について Fig.4 に示す、図より明らかなように, 電気抵抗は温 度の上昇に伴って減少する傾向にあり、半導体的な振 る舞いを示すが, 約 $800^{\circ} \mathrm{C} て ゙$ 勾配の異なる 2 つの直線

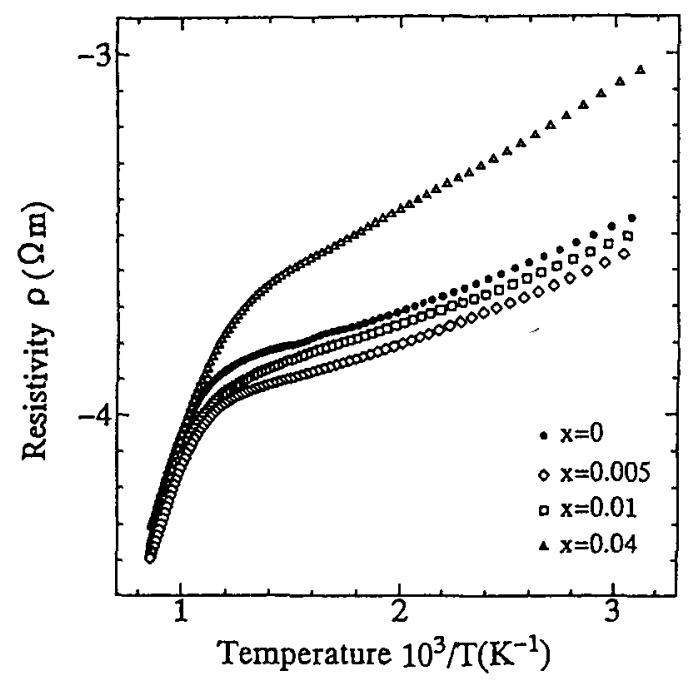

Fig.3 Temperature dependence of electrical resistivity for Fe0.98Co0.02Si2.xAlx $(0 \leqq X \leqq 0.04)$.

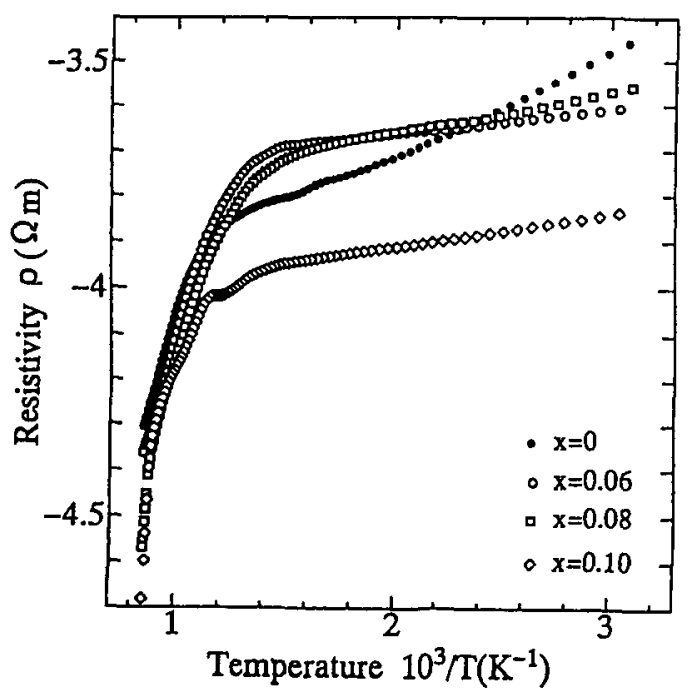

Fig.4 Temperature dependence of electrical resistivity for $\mathrm{Fe}_{0.98} \mathrm{C}_{00.02} \mathrm{Si}_{2 \cdot \mathrm{xAl}}$ $(0.06 \leqq X \leqq 0.1)$.
からなっており，それぞれの伝導機構が異なっている ことを示している. $800^{\circ} \mathrm{C}$ 以下では不純物伝導機構, $800^{\circ} \mathrm{C}$ 以上では固有伝導機棈であると考えられる，9) また, 低温領域での直線の勾配は， $\mathrm{Al}$ 添加量によって 明確に異なっており，伝導機構が Al 添加量によっても 大きく異なることがわかる，さらに，電気抵抗の值は $\mathrm{Al}$ 添加量の增大にともなって一旦減少した後増大し, $\mathrm{X}=0.04$ で最大值をとった後，再び減少する. この傾向 は, Fe0.98C00.02Si2 + ywt\%Al の場合も同様であり, $\mathrm{y}=1$ で最大值をとり，その前後で勾配が著しく異なってい ろ.

\section{3-3 熱起電力および出力因子}

Fig.5 に Fe0.98Co0.02 $\mathrm{Si}_{2} \cdot \mathrm{xAlx}(\mathrm{x}=0 \sim 0.1)$ の熱起電力の 温度依存性を示す、図より明らかなように, $0 \leqq \mathrm{X} \leqq$ 0.04 ではn型を保持しているが, $\mathrm{x} \geqq 0.06$ で急遮 $\mathrm{p}$ 型に 変化する. Fig.3で見られた電気抵抗の大きくなる Al 添加量は, $\mathrm{n}$ 型から $\mathrm{p}$ 型に変化する $\mathrm{Al}$ 添加量に相当し ており，Al の添加によって生ずる正孔によって電子が 相殺されて，キャリアー濃度が急激に減少するため， 電気抵抗が著しく大きくなったものと考えられる. $\mathrm{Al}$ 濃度がさらに增大すると，正孔濃度が増大し，再び 電気抵抗が小さくなるが，それに伴って熱起電力は低 下する.

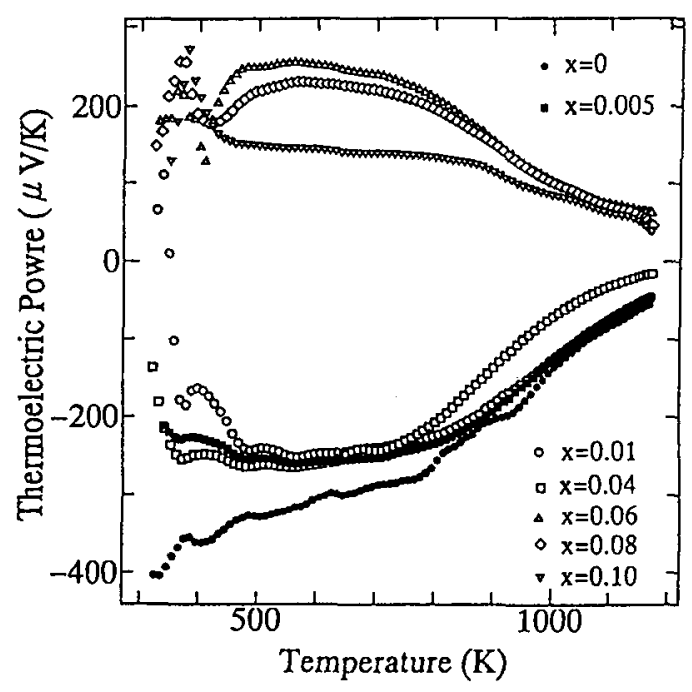

Fig.5 Temperature dependence of thermoelectrical power for $\mathrm{Fe}_{0.98} \mathrm{Co}_{0.02 \mathrm{Si}} \cdot \mathrm{xAl} x(\mathrm{x}=0 \sim 0.1)$.

Fig.6, 7 および 8 に, Fe0.98Co0.02Si2-xAlx(x=0 0.04) 
および $\mathrm{Fe} 0.98 \mathrm{Co0}_{02} \mathrm{Si}_{2}+\mathrm{ywt} \% \mathrm{Al}(\mathrm{y}=0 \sim 1),(\mathrm{y}=2 \sim 6)$ の場合について，上記の電気抵抗および熱起電力の值 より計算した出力因子(Q2/ $(2)$ の温度依存性をそれぞれ 示す.いずれの場合も， $\mathrm{Al}$ 添加量が少ない範囲では， $\mathrm{Al}$ 無添加とほぼ同じ大きな値をとるが， $\mathrm{Al}$ 添加量が 增大すると急激に低下し, $\mathrm{n}$ 型から $\mathrm{p}$ 型に変化する $\mathrm{Al}$ 添加量で，著しく小さな值をとる．さらに,Al 添加量 が増大すると，性能指数は再び增大するが, $\mathrm{y}=2$ 以外 は $\mathrm{Al}$ 無添加の場合より著しく小さな值となる.

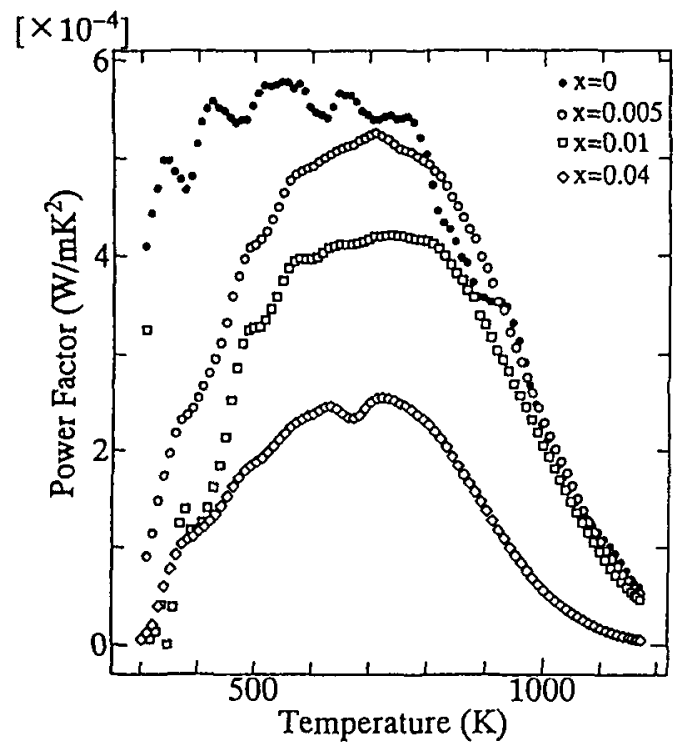

Fig.6 Temperature dependence of power factor for $\mathrm{Fe}_{0.98} \mathrm{Co0.02}_{0 .} \mathrm{Si}_{2} \times \mathrm{Al} x(x=0 \sim 0.04)$.

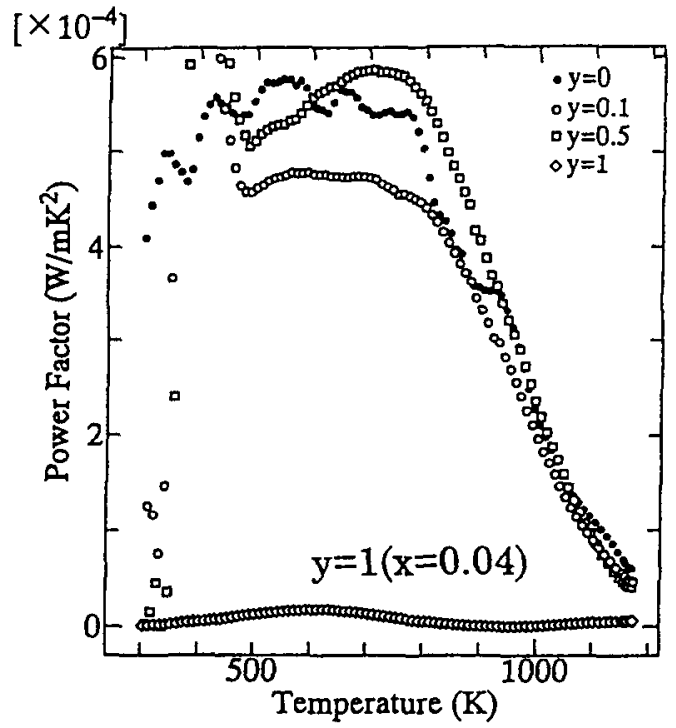

Fig.7 Temperature dependence of power factor for $\mathrm{Fe}_{0.98} \mathrm{C}_{00.02} \mathrm{Si}_{2}+\mathrm{ywt} \% \mathrm{Al}(\mathrm{y}=0 \sim 1)$.

\section{3-4 熱伝導率および性能指数}

一例として, Fig.9にFeo.88Co0.02Si ${ }_{2}+0.5 \mathrm{wt} \% \mathrm{Al} の$

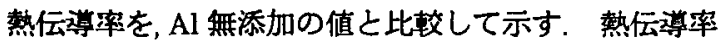
は, $\mathrm{Al}$ 添加によって僅かに増大する。 これは $\mathrm{Al}$ 添加 による比熱の増大に起因するものである.

Fig.7 の出力因子と，Fig.9 の熱伝導率より求めた $\mathrm{Fe}_{0.98} \mathrm{Co0}_{02} \mathrm{Si}_{2}+0.5 \mathrm{wt} \% \mathrm{Al}$ の性能指数 $\left(\mathrm{Q}^{2} / \rho \kappa\right)$ の温 度依存性を Fig.10 に示す。

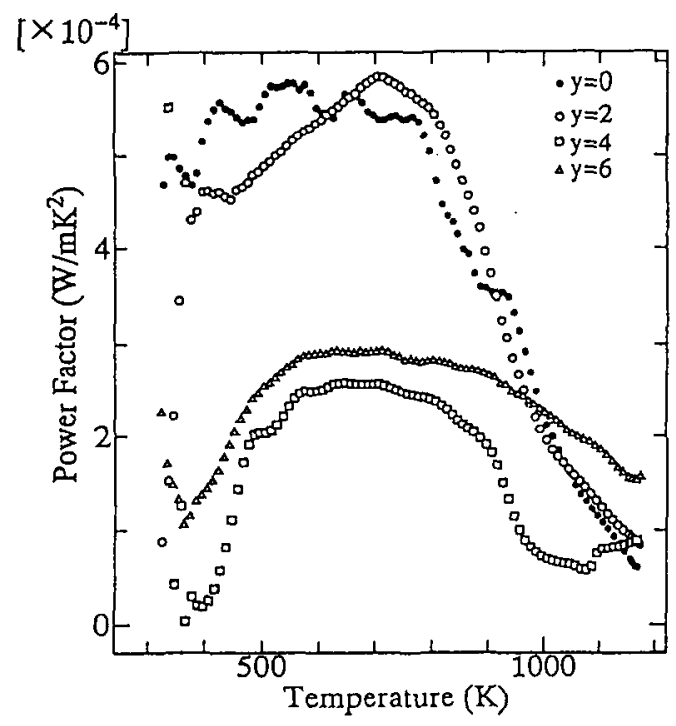

Fig.8 Temperature dependence of power factor for $\mathrm{Fe}_{0.98} \mathrm{Co}_{0.02} \mathrm{Si}_{2}+$ ywt\%Al $(y=2 \sim 6)$.

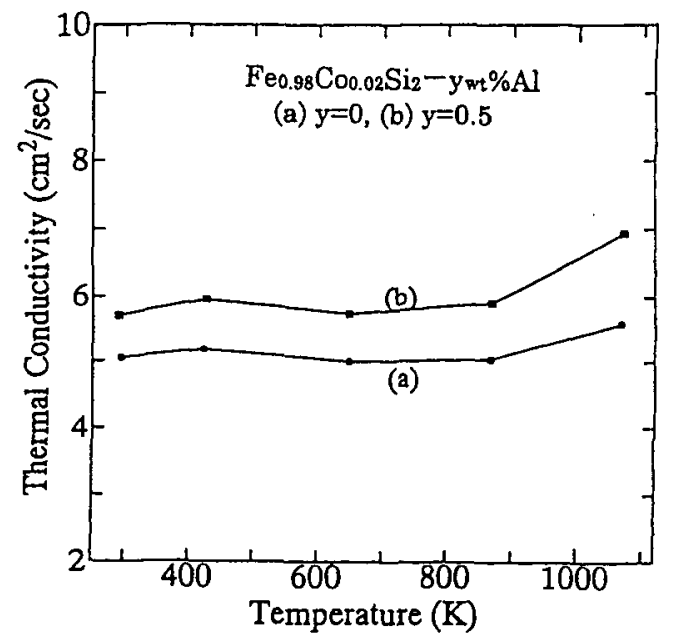

Fig.9 Temperature dependence of thermal conductivity for $\mathrm{Fe} 0.98 \mathrm{Co0.02} \mathrm{Si}_{2-}+0.5 \mathrm{wt} \% \mathrm{Al}$. 
$\mathrm{Al}$ 添加量が少量であろ場合は, 図より明らかなように, $\mathrm{Al}$ 添加によって性能指数は殆ど低下しないか， $\mathrm{n}$ 型 $\beta$ $\mathrm{FeSi}_{2}$ に多量の $\mathrm{Al}$ が入った場合には，著しく性能が低 下することか，出力因子の結果より予想される，した がって，Co を添加した $\mathrm{n}$ 型 $\beta \cdot \mathrm{FeSi}_{2}$ と $\mathrm{Al}$ を添加した $\mathrm{p}$ 型 $\beta-\mathrm{FeSi}_{2}$ とを $\mathrm{p}-\mathrm{n}$ 接合して熱電素子を作製した場合 には， $\mathrm{A}$ の拡散による性能の分化などには配虑が必要 となるものと予想される.

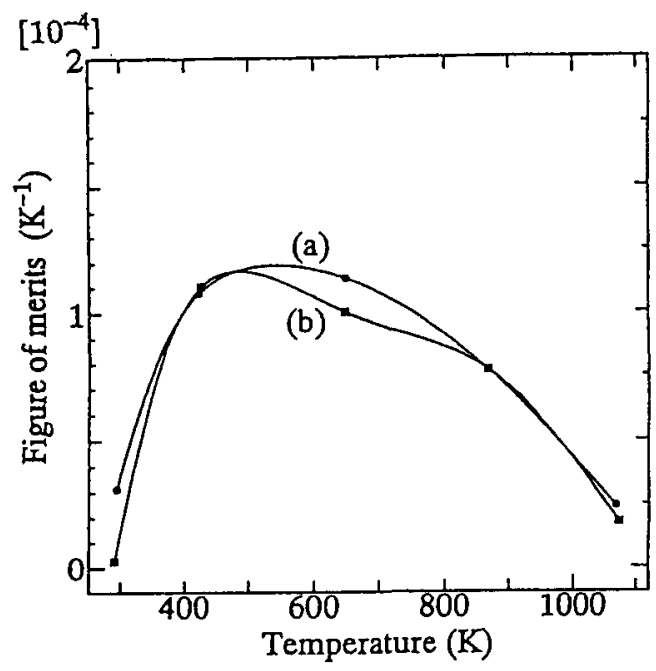

Fig.10 Temperature dependence of the figure of merit for $\mathrm{Fe}_{0.98} \mathrm{CO}_{0.02 \mathrm{Si}}$ - + 0.5wt\%Al.

\section{4 結 言}

$\mathrm{n}$ 型 $\mathrm{Fe} 0.98 \mathrm{Co0.02} \mathrm{Si}_{2}$ の熱電特性に及ぼす $\mathrm{Al}$ 添加の影 響について検討し、以下の結果を得た。

1） $\mathrm{Al}$ 添加量の変化に対応して伝導機構が著しく変化 ᄂ, $\mathrm{Fe}_{0.98} \mathrm{Co0}_{0.02} \mathrm{Si}_{2} \times \mathrm{Xlx}(\mathrm{X}=0.04)$ 及び Fe0.88Co0.02Si2 + $y w t \% A l(y=1) の \mathrm{Al}$ 濃度で電気抵抗值が著しく增大し

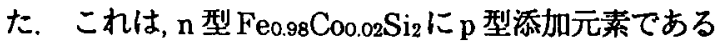
$\mathrm{Al}$ を添加することによって，電子がホールによって相
殺されることにより，キャリアー濃度が著しく減少す るためであると考えられる.

2) $\mathrm{Al}$ 添加量が $0 \leqq \mathrm{X} \leqq 0.04$ および $0 \leqq \mathrm{y} \leqq 1$ では $\mathrm{n}$ 型 を保持するが， $0.06 \leqq \mathrm{X}$ および $2 \leqq \mathrm{y} て ゙ は \mathrm{p}$ 型に変化す ろ. 出力因子は, $\mathrm{Al}$ 添加量が僅かである場合は, $\mathrm{Al}$ 無 添加と比較して余り減少しないが, $\mathrm{Al}$ 添加量が増大す ると急激に低下する。

3）熱伝導率は， $\mathrm{Al}$ 添加によって僅かに增大するが， $\mathrm{Al}$ 添加量が僅かである昜合には，性能指数に及ぼす影 響は小さい.

\section{謝 辞}

本研究の一部は、文部省科学研究費試験研究(B)によ り研究助成を受けたことを記し，感謝の意を表します。

\section{文 献}

1) I. Nishida : Phys. Rev., B7(1973)2710.

2) R.W.Ware and D.J.McNeil : Proc. IEE., 111 (1964)178.

3) U.Birkholz and J.Schelm : Phys. Stat. Sol., 27 (1968) 413.

4) T.Kojima, M.Okamoto and I.Nishida : Proc. 5th Int. Conf. Thermoelectric Energy Conversion, Arlington, (1984) 56.

5) 永井 宏, 中山祥吾, 勝山茂, 真島一彦: 粉体お よび粉末冶金,42(1995), 1323.

6）永井 宏, 中山样吾, 勝山 茂, 真島一彦: 粉体お よび粉末冾金,42(1995), 151.

7）渡辺哲也，羽坂雅之，宮瀬甞德：日本金属学会誌， 58(1994)353.

8）志賀信哉，梅本 実，岡根 功：粉体および羒末冶 金,42(1995)141.

9）坂田民雄，西田勲男 ：日本金属学会誌 15(1976) 11. 